\title{
Understanding the Change and Development of Trust and the Implications for New Leaders
}

\author{
Kurt T. Dirks ${ }^{1} \cdot$ Patrick J. Sweeney $^{2} \cdot$ Nikolaos Dimotakis $^{3} \cdot$ Todd Woodruff $^{4}$
}

Received: 22 December 2020 / Accepted: 19 July 2021

(c) The Author(s), under exclusive licence to Springer Nature B.V. 2021

\begin{abstract}
Leaders, particularly new leaders, seek to establish high levels of trust, as it has been associated with higher levels of effectiveness and group outcomes. This study is designed to understand how trust changes and develops for leaders in a new role and the implications of that change. Although calls for research on trust over time have been made for the past 2 decades, our knowledge of this phenomenon is still quite limited. The findings indicate that leader and unit performance is a function not only of absolute trust level, but is also affected by the direction and magnitude of change in trust across time periods, with the highest levels of effectiveness being associated with leaders who exhibited an increase in trust from the group over time. The data also suggest that the direction and rate at which trust grew was determined by initial expectations and transformational leadership behaviors.
\end{abstract}

Keywords Trust $\cdot$ Leadership $\cdot$ Change

\section{Introduction}

When starting a new role, leaders typically desire to establish a high level of credibility and trust. Empirical research is consistent with this idea, having established that trust in a leader is positively associated with performance. As a result, leaders are advised to be highly trusted from day 1 , as expressed by management author Stephen Covey: "The first job of a leader is to inspire trust."

Although leaders can attempt to increase trust during this period, there is the equal potential to lose trust. The rate of increase or decrease also can vary from high to very low.

Kurt T. Dirks and Patrick J. Sweeney are listed alphabetically and contributed equally to this paper.

Kurt T. Dirks

dirks@wustl.edu

1 Olin Business School, Washington University in St. Louis, St. Louis, MO 63130, USA

2 School of Business, Wake Forest University, P.O. Box 7897, Winston-Salem, NC 27109, USA

3 Spears School of Business, Oklahoma State University, Stillwater, OK 74075, USA

4 United States Military Academy, 606 Thayer Road, West Point, NY 10996, USA
Indeed, trust is dynamic by nature, and it is particularly susceptible to change during this critical initial period. New leaders would benefit by understanding what determines the trajectory of trust as they start a new role and how this trajectory may impact their success. Existing research has begun to study changes in trust, but this work is in its early stages and important questions remain.

One question involves the implications of change in trust for leader performance. Many studies have demonstrated that higher levels of trust are associated with better outcomes compared to lower levels of trust (Burke et al., 2007; Colquitt et al., 2007; Dirks \& Ferrin, 2002). The studies were designed to understand the relationships between the levels of trust and outcomes at given points in time, but they do not account for the fact that leaders arrive at a given level of trust through different trajectories. For example, some leaders may establish a moderate to high level of trust immediately. Other leaders, including those with minority status, may start with low levels of trust and need to build trust over time. Other leaders may start with high trust and experience a drop over their first months. Thus, as illustrated in Fig. 1, although leaders arrive at an identical level of trust, their situations seem substantively different. Supporting this notion, Vogelgesang et al. (2021) recently found that the trajectory of trust produced important differences in how 


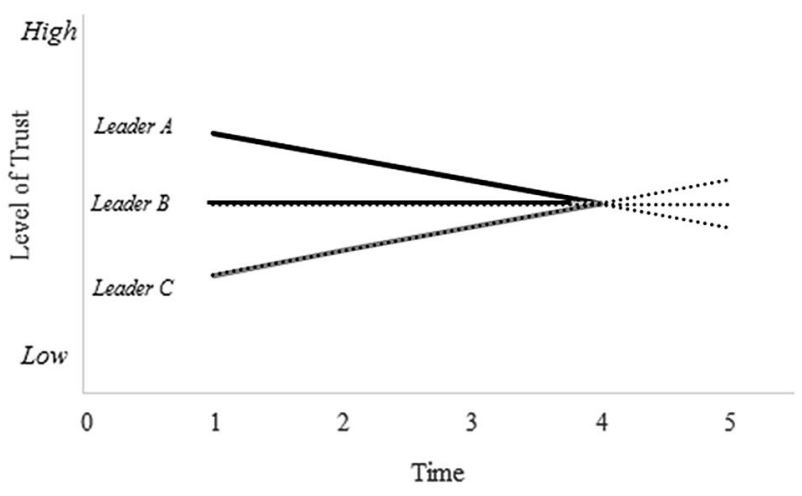

Fig. 1 Hypothetical leaders with different trust velocities over time

leaders were viewed. Does the trajectory of trust also have implications for the effectiveness of new leaders?

A second question involves understanding factors that govern the direction and rate of change in trust for new leaders. Research has discussed initial trust (McKnight et al., 1998) and presumptive trust (Kramer \& Lewicki, 2010), but empirical research has not studied how trust evolves beyond this starting point. Likewise, research has identified factors that predict the level of trust at particular points in a relationship, but it has rarely examined how trust changes to arrive at a given level. Recognizing this gap, van der Werf and Buckley (2017) designed a study to examine the trust development processes among coworkers. Their within-subjects longitudinal design allowed them to identify the key cues used by employees, which would not have been possible using a design focused on the level of trust. A similar approach could provide important insights for how trust in leaders develops and changes when they begin a new role.

The paper makes several contributions to the literature on trust and business ethics. First, it provides new insights for the impact of trust in leaders on performance outcomes. Specifically, the paper is perhaps the first to reveal how changes in trust that a group of employees have for their leader affect the level of performance for individuals and units beyond the level of trust. This research alters the guidance for leaders regarding trust when they take over a new role. It also highlights that past research has missed an important temporal factor in the study of trust, and suggests a new area for future research.

Second, the paper provides new insights for the development of trust in leaders. Reviews have repeatedly called for this type of work over the past two decades (see observations by Dirks \& Ferrin, 2002; Fulmer \& Dirks, 2018; Grossman \& Fetosa, 2018; Korsgaard et al., 2018; Lewicki et al., 2006). The present paper identifies two factors (a starting condition, and a set of behaviors) which determine the rate and direction of change in trust for leaders who step into a new role.
Third, the results reveal that transformational leadership, an ethics-based leadership style, accelerates the development of trust between leaders and followers. Previous research has found that leaders' ethical behavior was positively related to followers' trust, the establishment of an ethical climate, and leader and organizational effectiveness (Carlson \& Perrewe, 1995; Castaldo et al., 2010; Parry \& Proctor-Thomson, 2002; $\mathrm{Su}, 2014)$. The present study demonstrates the importance of leaders engaging in this behavior from the first day, and provides additional insight into the impact on trust over time.

Fourth, the study focuses on a particularly critical time for leaders when it comes to trust. When leaders take on a new role (e.g., through promotion, transfer, new hire, merger), they are under great scrutiny from followers seeking to understand the implications of working with them. Consequently, new leaders are particularly interested in establishing trust and credibility.

\section{Theory and Hypotheses}

Trust is conceptualized as "a psychological state comprising the intention to accept vulnerability based upon positive expectations of the intentions or behavior of another" (Rousseau et al., 1998, p. 395). In the present study, we focus on the trust of a group of individuals who report to a given leader and examine its associations with group performance. We focus on the overall group level of trust, which has been the dominant approach in the current literature (de Jong et al., 2016). Research has recognized the variation that exists among team members (e.g., de Jong et al., 2020). The focus of the present paper is the direction and rate of change of the overall level of trust, as opposed to changes in consensus that may be better considered in future research.

Social exchange is an underlying theoretical framework for our paper. It is particularly appropriate as change and development are inherent in the logic of social exchange. Researchers have frequently characterized trust in leaders as operating according to a social exchange process both in terms of the outcomes (e.g., Konovsky \& Pugh, 1994) and antecedents (e.g., Whitener et al., 1998). In social exchange, followers see the relationship with their leader as more than an economic contract (Blau, 1964), and they face uncertainty and risk based on their power differential. For example, followers share sensitive information and provide help or support when not required (Blau, 1964). Trust is critical for employees because it reduces uncertainty about the leader's motives and behavior, allowing them to willingly accept the leader's influence and focus energy on the organization's interests instead of their own, which should yield better outcomes for the leader and organization.

Social exchange provides a lens for examining trust changes over time. Through interactions, individuals gain 
evidence of their leader's trustworthiness, which will lead to changes in trust. For example, when expectations are not fulfilled, trust is expected to decrease. The resulting decreased level of trust serves as the basis for defensive behavior, fewer positive exchanges, and negative outcomes (Thibaut \& Kelley, 1986). For predictions, we integrate social exchange with extant trust theory to explain the change processes.

\section{Prior Research on Trust Change}

The conceptual literature has considered changes in trust from multiple perspectives including stage models, discontinuous changes, and linear trends (Korsgaard et al., 2018). Empirical studies, however, have not caught up. In their reviews, Dirks and Ferrin (2002), Lewicki et al. (2006), and Colquitt et al. (2007) all observed that most studies could be characterized as "snapshots" which measure trust and another variable at a single point in time. More recently, research has measured antecedents and consequences at different points in time to provide more confidence in inferences of causality (examples include de Jong \& Dirks, 2012; Ferrin et al., 2008; Serva et al., 2005). These studies identified predictors of the level of trust and its outcomes, using designs referred to as a "between-subjects" longitudinal study (Curran \& Bauer, 2011).

Recently, scholars have begun to conduct empirical studies using within-subject longitudinal designs to study dynamic processes because they allow the researcher to study questions not possible using between-subjects approaches, and/or to use change as a new concept/lens for examining existing questions. Van der Werff and Buckley's (2017) study of trust between coworkers was designed to test ideas from theories of trust development, for example, that trust develops in phases (e.g., Lewicki \& Bunker, 1996). Tracking trust between coworkers from their entry into the organization, researchers found that affect or relational signals of trustworthiness were important from the very beginning of the relationship and maintained importance across time, as opposed to only competence-related signals. This was important because it showed that several key tenets of current theories were not supported by data. Vogelgesang et al. (2021) studied the rate and direction of change in trust following a breach in a psychological contract. They emphasized that examining the change in trust, not just the level at a point in time, is important to study given that past events and trends are important in formulating current perceptions (e.g., whether the current level of trust was arrived at by increasing trust or decreasing trust). A third example using this approach is Drescher et al.'s (2014) study of how the emergence of group members sharing leadership roles led to changes in trust among team members, which in turn predicted change in performance. Thus, the study focused on the change in each variable (not level) at different time points, which was best studied using a within-subjects approach.

In sum, the handful of studies highlights the potential to consider key questions in the literature on trust, which is clearly a dynamic concept. For the research question of the present study, we adopt several of the distinctive features drawn from these earlier studies such as (a) tracking trust from the beginning of a relationship, instead of a point in the middle (van der Werff \& Buckley, 2017) (b) studying the rate and direction of trust as a concept (Vogelgesang et al., 2021), and (c) considering how changes in trust impact outcomes.

\section{Implications of Trust Change for Leader Effectiveness}

Nearly all of the existing research has focused on higher levels of trust being associated with higher levels of leader and unit-level effectiveness. Drescher et al. (2014) showed that changes in trust can predict changes in team performance (change predicts change). We depart from this earlier work by proposing that changes in trust are associated with higher levels of leader and unit effectiveness, above and beyond the effect of the level of trust.

We combine the logic of social exchange theory for trust, with theories of decision heuristics used in these earlier studies of change in satisfaction and commitment (Chen et al., 2011; Palmatier et al., 2013). For example, Chen et al. (2011) proposed that the level of an attitude or perception at an earlier point in time provides a reference point for interpreting that construct at the subsequent point in time. The attitude or perception becomes more salient because it increases or decreases from this reference point. The increased salience magnifies the impact of that construct. They found that changes in job satisfaction predict turnover above and beyond the level of satisfaction. Similarly, Rosen et al. (2020) demonstrated that change, versus stability, resulted in a higher impact of stressors on performance, presumably due to increased salience.

This change in salience is equally critical to understanding the effect of changing trust. As trust is growing, individuals think more about their high trust in the leader compared to a leader who already has high stable trust. The increased salience accentuates the benefits of trust, thus increasing performance. Conversely, if trust declines, the decreasing trust and sense of vulnerability becomes salient, thus increasing the energy devoted toward monitoring, selfprotection, and self-focused goals (as opposed to exchange behaviors directed toward the group), which will result in decreased group performance. In this way, high and growing trust is more beneficial than high stable trust and low declining trust more deleterious than low stable trust. 
A related process involves the idea that change is associated with perceptions of momentum in a relationship, which impacts how individuals act (Palmatier et al., 2013). According to decision heuristic theory, individuals consider perceived trends in their decisions regarding how to interact in their relationship. Thus, when individuals believe a relationship is growing, they think and act as if that direction and rate will continue. Alternatively, if individuals sense that the relationship is declining, they will act accordingly. To illustrate this idea, we return to the illustration in Fig. 1. The dashed lines that start at Time 4 represent potential future velocities of trust in each leader. According to decision heuristic theory, observers would expect the momentum for each leader to persist. Thus, observers expect the upward trajectory to continue for Leader $\mathrm{C}$, whereas they would expect the downward trajectory to continue for Leader A. In summary, followers tend to notice when trust changes, which triggers heuristic processing that the trend will continue.

As an example, consider two leaders who are equally trusted 6 months into their new roles. In one case, the level of trust has been high and stable since the beginning of the relationship. Followers have settled into a way of working with that leader based on this level of trust. In the second case, the level of trust started out at a moderate level. As the leader has consistently exceeded initial expectations, the level of trust has steadily grown. In the first case, followers expect leader trustworthiness to remain unchanged in the future, but the followers who have experienced growing trust will expect their leader's trustworthiness to continue to increase. As a result, followers with a similar level and growing trust will focus less on personal concerns and interests, and more on a positive feeling of working toward the collective goal and a sense of momentum. Hence, we would expect their level of performance to end up higher than in the case of leaders who start with high levels of trust and simply maintain it. When combined with the earlier argument, trust in the leader is more salient for those individuals who perceive trust as growing, and they think and act as if that direction and rate will continue in the future. The combination of increased salience and the expectation of continued growth suggests that growing trust is more impactful than an equal level of stable trust.

Ultimately, we would expect that the levels of leader effectiveness derived from trust development will translate into higher levels of unit effectiveness. More effective leaders will be better able to create cohesion that enables units to function better (Bass et al., 2003), and ultimately help the unit best meet its objectives.

Hypothesis 1: For a given level of trust, leaders who experienced an increase in trust will be rated as more effective compared to leaders who experienced stable or declining trust. The greater the change in trust, the greater the leader effectiveness.

Hypothesis 2: Increases in trust will be indirectly associated with unit performance via leader effectiveness.

\section{Predicting the Direction and Rate of Change in Trust for New Leader Relationships}

The above section proposes that it is not only the level of trust at the given point in time that matters, but also the trajectory by which a leader arrives at that level of trust. In this section, we explore two key factors that govern the direction and rate at which trust changes.

To recap, social exchange theory posits that trust facilitates exchanges between individuals. Over time, the interactions that occur between individuals establish trust and dictate how trust changes. In the present study, we are interested in understanding how this happens for leaders who step into a new role. Although trust has a slight tendency to increase over time (see meta-analysis by Vanneste et al., 2014), it is reasonable to expect that the level of trust in a relationship can increase, decrease, or stay the same at any point. Change, however, is most likely to occur early in the relationship, as information is revealed.

\section{Initial Expectations as a Predictor of Change in Trust for a New Leader}

Employees typically have had little or no prior interaction with a new leader and thus must operate on initial expectations to start the social exchange process. Leadership researchers have discussed that employees have implicit assumptions about the attributes of a good and effective leader in a context and that these shape their expectations (Lord et al., 1984). Individuals will draw on cues from personal attributes, social connections, and situational contexts as sources of information to form their initial expectations regarding a person, particularly as related to trust (Bacharach \& Gambetta, 2001). For example, personal attributes such as age, race, gender, body language, or presence can all impact initial expectations related to trust.

Expectations impact the level of trust; indeed, most conceptualizations indicate that trust is based upon positive expectations (Kramer \& Lewicki, 2010). Thus, it is straightforward to expect that higher expectations are associated with a higher initial level of trust, and low expectations will be associated with low initial levels of trust. McKnight et al. (1998) hinted that initial expectations, however, also play a role in how trust changes over time. Below we propose that whereas expectations are positively associated with the initial level of trust, they are negatively associated with the rate and change in trust. 
Boyle and Bonacich (1970) theorized that change in trust is based on the extent to which a behavior provides different or new information, particularly from prior expectations. High expectations present a difficult standard for leaders to maintain, and thus sets up a potential for expectation violations. Over time, we expect leaders to engage in behaviors which comprise a distribution in which some behaviors will be seen as positive by followers (good outcomes, fair treatment, and so on), and other behaviors will be seen as negative (perceived integrity breach, errors, involvement in conflict, and so on). For trust, a single negative occurrence can decrease trust substantially and make it difficult to rebuild (Kim et al., 2004). Thus, a leader who starts with high expectations has a greater potential to experience a decline in trust because (a) they have a higher likelihood of violating expectations ${ }^{1}$ than someone who starts with lower expectations, and (b) a violation is likely to be seen as reason to revise trust downward. Using this same logic, low initial expectations are easier to exceed with a distribution of behaviors and thus are predictive of a positive change in trust.

Boyle and Bonacich (1970) also posited that the degree of change will be a function of the difference between expectations and subsequent behavior. This is similar to a contrast effect-i.e., the contrast between initial expectations and subsequent behavior. Thus, higher expectations have potential for a greater rate of decrease in trust, all other things equal.

It is important to note that the arguments described above, particularly those involving the rate of change, are different from a "regression to the mean" effect. The latter involves random variation, whereas the present prediction is a psychologically driven phenomenon.

Hypothesis 3: Initial expectations will be related to changes in trust. The higher the initial level of follower expectations, the steeper the resulting decline in trust over time, whereas the lower the initial levels of follower expectations, the steeper the resulting increase in trust over time.

\section{Leader Behavior as a Predictor of Rate of Change in Trust}

Once the relationship moves beyond the initial interaction, leader behaviors become the active ingredient for social exchange and the determinant of trust (Blau, 1964). Past research has demonstrated that various leadership behaviors are highly predictive of the level of follower's trust. Transformational leadership is the style most frequently associated with trust, and it has shown a strong, positive

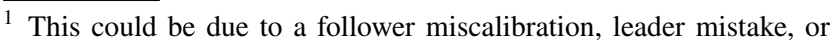
intentional act. All will lead to a drop in trust.
}

correlation with the level of trust (Dirks \& Ferrin, 2002). Transformational leadership is comprised of several categories of behavior including idealized influence, inspirational motivation, individual consideration, and intellectual stimulation. Transformational leaders demonstrate individual consideration when they engage in behaviors to meet individuals' needs and promote their development. Leaders who take actions based on an internalized set of values and who place followers' needs before their own demonstrate idealized influence. Inspirational motivation is achieved when leaders engage in behaviors that enhance the meaning of challenge group members find in their work. Leaders provide followers intellectual stimulation by encouraging them to question old ways of doing things, view problems from different perspectives, and empower them to creatively solve problems (Bass, 1999). These behaviors are seen as evidence for all aspects of trustworthiness-that leaders are competent, possess good character, and care about their followers. For example, idealized influence is useful for demonstrating competence and character, while the behaviors of individualized consideration provide evidence of care.

As noted earlier, Boyle and Bonacich (1970) proposed that change in trust is based on the extent to which a behavior provided different or new information, particularly from prior expectations. Therefore, in leader-follower relationships, the rate of change in trust will be based on the degree to which leaders demonstrate evidence of trustworthiness that is new or different from employees' initial expectations or presumptive trust (Kramer \& Lewicki, 2010). Vogelgesang et al. (2021) provided an example of this idea as they demonstrated that a breach in psychological contract in the course of a relationship (presumably novel information) impacts the rate of change in trust. We assume that followers have limited and incomplete information about the trustworthiness of leaders at the beginning of relationship, and hence behaviors frequently reveal new information. Thus, when leaders provide evidence about multiple aspects of trustworthiness through their behaviors, a significant change in trust will result (Mayer et al., 1995).

This idea makes transformational leadership particularly powerful in determining the rate of change in trust early in a relationship, because it can provide new or additional evidence of multiple forms of trustworthiness. As one example, transformational leadership includes individualized consideration behavior, which provides evidence of the "affective" or relational aspects of trust. Evidence of care and concern early in the relationship increases trust (see van der Werff $\&$ Buckley, 2017). Relational aspects are not (fully) evident prior to interacting with the leader, however, and thus transformational leadership provides new or more complete information. Other facets of transformational leadership provide the follower with new evidence of values or of capability of the leader which further increase the rate of change in 
trust. In summary, given the limited information available at the start of the relationship, the more leaders engage in transformational leadership behaviors, the more they reveal new and rich information, and hence the faster the rate of change in trust.

Hypothesis 4: Transformational leadership will be related to changes in trust. The higher the level of transformational leadership, the steeper the resulting increase in trust over time, while the lower the level of transformational leadership, the steeper the resulting decrease in trust over time.

\section{Methods}

\section{Participants}

Data were gathered at the United States Military Academy, which describes itself as "the world's premier leader development institution" (United States Military Academy, 2010). Study participants were cadets who attended the Academy to simultaneously earn college degrees and gain officer commissions in the United States Army upon graduation.

This setting and sample provided several notable characteristics for the present study. First, cadets were assigned to units and thus, to leaders, by a computer algorithm which strived to maximize diversity (e.g., gender, collegiate athletes, race). This semi-random assignment procedure allowed us to rule out a selection effect in which individuals might develop trust rapidly because they were chosen by the leader or they chose to work for that leader. Second, we were able to collect initial trust measures at the very beginning of the leader-follower relationship and to continue measuring trust as the relationship developed. Specifically, at the beginning of the study, the design of the system was such that the leadership in all 15 units that participated in the study was entirely new, and the direct supervisors and followers did not know each other. Although cadets knew that the Army had placed the individuals in the positions, they had little or no information about the leaders' specific abilities, values, or other attributes. Third, the context involved holding a number of factors constant including (a) all relationships started at the same time (which eliminated organizational maturation or cross-cohort effects), (b) the formal structure of leadership roles was identical across organizations, and (c) leader appearance was highly uniform (same dress, age, and bearing).

As part of the military leadership development program, cadets were organized into a hierarchy with a regiment having companies ( 9 companies per regiment), platoons (4 platoons per company), and squads (4 squads per platoon with approximately 8 cadets in each squad). Our sample involved squad members, the focal leader they reported to, and the superior leader(s) of the latter.

Data were collected from squad members, who responded about their trust in their direct leader, and from the leadership one level above this direct leader, who responded about unit effectiveness. Direct leaders were cadet squad leaders who had been appointed to the role by the tactical officer (United States Army Captain or Major) and senior cadet leadership in the company. Squad leaders, who are third year cadets with 2 years of leadership preparation at West Point, have an important set of responsibilities that include: socializing and developing peers and the under-class cadets; planning, coordinating, and executing training and daily operational requirements; enforcing standards; maintaining good morale and discipline; ensuring cadets met academic, physical, and military standards; keeping their followers informed; and establishing a positive organizational climate.

\section{Procedure}

The data we used to test our hypotheses were collected at three time points, with an additional time point collected to check for non-linearity in the growth model (for a total of four time points). Time 1 data were collected during the first week of the academic program. The week prior to the data collection, the new company leadership engaged in activities to learn their duties, integrate new cadets into the organization, access equipment and materials needed for the academic year, and start to build a team. All the leaders were new to their positions at the start of the study and the squad members had not interacted with them previously. Times 2 and 3 data collections were conducted approximately 5 weeks apart throughout the semester. The main data collection was completed just prior to the start of final exams (at approximately Time 3); at this time leader and group effectiveness data were also collected. Due to data collection constraints, the Time 4 data collection could only be conducted after the assessment to Time 3 mediator and dependent variables, and thus could not be used in the models predicting the effects of trust change. However, it provided an additional datapoint that allowed for the testing of non-linear effects in the models predicting trust trajectories. See the variables section below for specific measurement times for all study variables.

A personalized invitation to participate in a survey was emailed to approximately 720 squad members. The e-mail included a description of the study and a PIN (personal identification number) that allowed them to voluntarily participate in a confidential manner. During the first round of data collection, 545 squad members participated which represented a $76 \%$ response rate. Three more waves of data were collected using the same procedure. The response rate for Time 2 was $49 \%(n=354)$, Time 3 was $47 \%(n=343)$, 
and Time 4 (the supplemental data collection) was $41 \%$ $(n=296)$. Consistent with the military population, $82 \%$ of the respondents were male.

It was important that we be able to match the respondent across waves. Therefore, we excluded those cases where we could not identify the respondent or the respondent's data from a single wave were incomplete. The final sample for the analyses was comprised of 534 individual squad members each nested within one of 130 squads. Each cadet was assessed between one and four times resulting in a total of 1327 person-by-time observations with 140 cadets being assessed only once, 125 being assessed twice, 135 being assessed three times, and 133 being assessed four times. Multilevel models utilized all available data and assumed that missing data were missing at random (MAR), which is in accordance with best practices (Allison, 2002). ${ }^{2}$ Thus, this practice allows respondents to be included in the sample even when they did not participate in all waves of data collection. All squad member responses were aggregated to the level of the focal leader. Combined with available higher level leader reports, our final sample consisted of 111 leaders with complete data across all study periods.

\section{Measures}

\section{Initial Expectations of Leader}

A 4-item measure was created based on a review of the person and leader perception literature (Hall \& Lord, 1995; Macrae \& Quadflieg, 2010; Offermann et al., 1994). At Time 1 , squad members rated their expectations for their new squad leader using a 7-point Likert-type agreement scale ( $1=$ strongly disagree, $7=$ strongly agree). Sample items included: "I expect to like my squad leader" and "I expect my squad leader to be an effective leader" (See Appendix A). Reliability for this scale was $\alpha=0.87$. Inter-rater agreement was $R_{\mathrm{wg}}=0.78$, supporting aggregation to the level of the leader.

\section{Trust}

Squad members assessed trust in their direct supervisors, at all three data collections, using an 8-item scale adapted from the commonly used scale in McAllister (1995). Sample

\footnotetext{
${ }^{2}$ FIML estimation was thus utilized. Covariance coverage was above the recommended .75 threshold (Enders \& Bandalos, 2001). To ensure data were MAR, we conducted a series of binomial regression analyses to ensure that missingness of variables at a given time was not predicted from study variables at prior times (for example, that T3 variables were not a function of $\mathrm{T} 1$ and $\mathrm{T} 2$ variables). No evidence was found to suggest data were not indeed missing at random, supporting our assumptions.
}

items included: "I can depend on my squad leader to meet his/her duties" and "I feel confident that my squad leader will always care about my personal needs in the squad setting." Participants used a 7-point scale, with anchors ranging from "strongly disagree" (1) to "strongly agree" (7), to assess each item (See Appendix A). Reliabilities ranged from $\alpha=0.95$ to 0.97 across time periods. For inter-rater agreement, $R_{\mathrm{wg}}$ ranged from 0.84 to 0.91 for the different time periods; this again suggested aggregation was appropriate.

\section{Transformational Leadership}

Members of squad assessed the frequency their direct supervisors engaged in transformational leadership behaviors, at Time 2, using 24 items from the Multi-factor Leadership Questionnaire (MLQ) 5X (Avolio \& Bass, 2004). ${ }^{3}$ This assessed idealized influence, inspirational motivation, individual consideration, and intellectual stimulation. The MLQ uses a 5 -point Likert-type scale $(0=$ not at all, $4=$ frequently, if not always). Reliability for this scale was $\alpha=0.97$. For inter-rater agreement, $R_{\mathrm{wg}}=0.78$, similar to the initial expectations variable.

\section{Leader Effectiveness}

At Time 3 squad members reported on leader effectiveness using a 6-item outcome measure created from the United States Army's three categories of leadership competencies (leads, develops, and achieves), outlined in ARDP 6-22. Each category outlines specific competencies Army leaders must demonstrate. Sample items to represent the competencies outlined in ARDP 6-22 included: "led by example," "positively impacted my development as a cadet," and "exercised leadership that was instrumental in the squad achieving all assigned objectives (i.e., got results)" (See Appendix A). Reliability for this scale was 0.96 . For inter-rater agreement, $R_{\mathrm{wg}}=0.93$.

\section{Squad Performance}

At Time 3, platoon leaders and platoon sergeants assessed each squad they supervised, using 3-item outcome measured based on the Army's three categories of leadership competencies outlined in ARDP 6-22. Platoon leaders and platoon sergeant used a 5-point Likert-type effectiveness scale to conduct their unit-level assessment of each squad $(1=$ not effective; $5=$ highly effective) (See Appendix A). Sample items included: "met or exceeded standards on all assigned tasks (i.e., got results)," and "worked together to enhance

\footnotetext{
${ }_{3}$ Used with permission of Bruce Avolio.
} 
each member's development." The alpha for this variable is 0.91 .

\section{Control Variables}

In all analyses, we controlled for average team GPA (expressed as class ranking), average team gender, and average team age. These controls were included due to their possible associations with performance and trust in the leader. In addition, the growth model predicting trust further controlled for average team agreeableness (measured with a five-adjective version of the markers from Goldberg, 1992; $\alpha=0.83$ ), as this personality trait has a relatively close association with expectations of trust. Results with these control variables omitted were essentially unchanged.

\section{Results}

\section{Analyses}

Due to the inherent nesting within our data, our study hypotheses were tested using multilevel modeling; all models were run in MPlus 7.11 and utilized a full information maximum likelihood approach (see Enders \& Bandalos, 2001). Depending on the hypothesis being tested, the nesting structure of the data differed due to changes in the unit of analysis and the source of non-independence. The models testing the effects of trust change on leader effectiveness and squad effectiveness involved observations nested within raters (of squad effectiveness: platoon leaders and sergeants). For the growth models testing our second set of hypotheses, squad reports at four times were nested within focal leaders to account for non-independence of trust ratings by squad members. More simply, the first set of models used a "wide" data structure, testing the interactive effect of trust at Time 1 and Time 2 on Time 3 measures of leader and squad effectiveness, while the second set of models used a "long" data structure, testing the effects of time $(T 1=1$, $T 2=2$, and so forth) on initial levels of trust and on trust development.

We selected and adapted an analytical technique best suited to test our hypotheses. To test the effects of trust change across time periods (Hypotheses 1 and 2) we utilized a polynomial regression approach (Edwards, 2002), modified for use in multilevel models. This analytic technique has been increasingly used in recent years to examine change processes, including in multilevel contexts (e.g., Jansen et al., 2016; Tepper et al., 2018; Rosen et al., 2020). As with these earlier studies, polynomial regression was chosen over other sophisticated analytical approaches, such as latent change models, because of the hypothesized and expected asymmetries between different change conditions as well as the comparison of change versus stability inherent in our discussion (see Edwards \& Parry, 1993; Edwards, 2001 for a discussion). The polynomial regression model required fewer assumptions about the direction and relative magnitude of different forms of change. For example, polynomial regression does not require the assumption that decreases and increases operate in forms equal in magnitude but opposite in sign. This assumption would not fit with our theory for how change in trust predicts outcomes. Since it is a newer approach, we examine its robustness later in this paper.

The polynomial approach involves estimating a model of the form:

$$
\begin{aligned}
\text { Leadership Effectiveness }= & b_{0}+b_{1} T_{1}+b_{2} T_{2}+b_{3} T_{1}^{2} \\
& +b_{4} T_{1} T_{2}+b_{5} T_{2}^{2}
\end{aligned}
$$

where $T_{1}$ represents Trust at $T 1$ and $T_{2}$ represents Trust at $T 2 .{ }^{4}$ Results from this model were used to calculate a number of derived estimates that directly test our hypotheses. The effects of trust change are directly tested by the change curve (what would traditionally be called the misfit curve; calculated as $b_{3}-b_{4}+b_{5}$ ). This estimate indicates whether change (as opposed to stability) in trust is associated with increased or decreased perceptions of leader effectiveness. A positive change curve means that change is associated with higher leader effectiveness than stability, with the opposite being true for a negative curve.

This test combines with the change slope (what would traditionally be called the misfit slope; calculated as $b_{1}-b_{2}$ ) to indicate (if change is indeed more closely associated with effectiveness than stability) whether increases or decreases in trust are associated with higher levels of perceived leader effectiveness. A positive change slope indicates that, overall, increases are positively associated with leader effectiveness compared to decreases.

The stability slope (what would traditionally called the fit slope; calculated as $b_{1}+b_{2}$ ) tests whether squads that experienced stable and high trust in their leader perceived that leader to be more effective (as opposed to squads that experienced stable and low trust). A positive slope indicates that high (and stable) trust is associated with higher leader effectiveness compared to low (and stable) trust. Finally, while not directly hypothesized, the stability curve (traditionally, the fit curve; calculated as $b_{3}+b_{4}+b_{5}$ ) tests whether the magnitude of the effects of stable trust changed for squads

\footnotetext{
$\overline{4}$ We started with $\mathrm{T} 1$ and $\mathrm{T} 2$ measures of trust as the primary periods under comparison, in order to create sufficient temporal separation to alleviate common methods concerns (as the leader effectiveness variable was measured at T3). To ensure, however, that our effects were stable and not contingent on specific measurement periods, we then reran the model utilizing $\mathrm{T} 1$ and $\mathrm{T} 3$ and then $\mathrm{T} 2$ and $\mathrm{T} 3$ as the observations comprising the comparisons.
} 
Table 1 Means, standard deviations, and intercorrelations among variables in this study

\begin{tabular}{|c|c|c|c|c|c|c|c|c|c|c|c|c|c|c|}
\hline & & M & SD & 1 & 2 & 3 & 4 & 5 & 6 & 7 & 8 & 9 & 10 & 11 \\
\hline 1 & Average team gender & 0.88 & 0.32 & & & & & & & & & & & \\
\hline 2 & Average team GPA rank & 245.12 & 82.56 & -0.12 & & & & & & & & & & \\
\hline 3 & Average team age & 20.50 & 1.08 & 0.14 & -0.08 & & & & & & & & & \\
\hline 4 & Average team agreeableness & 5.95 & 0.41 & 0.14 & 0.04 & -0.14 & & & & & & & & \\
\hline 5 & Initial expectations & 5.96 & 0.53 & 0.08 & 0.03 & -0.14 & 0.34 & & & & & & & \\
\hline 6 & Transformational leadership & 3.83 & 0.58 & 0.03 & 0.06 & 0.22 & 0.22 & 0.47 & & & & & & \\
\hline 7 & T1 trust & 6.02 & 0.50 & 0.14 & 0.07 & 0.46 & 0.46 & 0.76 & 0.45 & & & & & \\
\hline 8 & $\mathrm{~T} 2$ trust & 6.04 & 0.73 & -0.01 & 0.00 & 0.16 & 0.15 & 0.28 & 0.66 & 0.32 & & & & \\
\hline 9 & $\mathrm{~T} 3$ trust & 5.98 & 0.69 & 0.14 & 0.13 & -0.07 & -0.05 & 0.10 & 0.28 & 0.10 & 0.31 & & & \\
\hline 10 & $\mathrm{~T} 4$ trust & 5.92 & 0.76 & -0.07 & 0.10 & -0.13 & -0.07 & 0.05 & 0.34 & 0.07 & 0.36 & 0.52 & & \\
\hline 11 & Leader effectiveness & 4.04 & 0.62 & 0.22 & 0.16 & 0.04 & 0.04 & 0.23 & 0.47 & 0.24 & 0.34 & 0.83 & 0.46 & \\
\hline 12 & Squad effectiveness & 3.79 & 0.66 & -0.08 & 0.01 & -0.14 & -0.14 & 0.07 & 0.17 & 0.21 & 0.20 & 0.21 & 0.21 & 0.20 \\
\hline
\end{tabular}

$N=111$ observations nested within 41 raters. Correlations of absolute magnitude above 0.19 are significant at $p<0.05$

$* p<0.05$

$* * p<0.01$

at particularly high (or low) levels of trust that were stable over time.

To test the indirect effects of trust increase, stability, and decrease on squad performance through leader effectiveness (Hypothesis 2), we employed the contemporary approach of Rosen et al. (2020). In this approach, we calculated estimates for the effects of changing trust in the regions of increase and decrease, as well as an overall effect for stable trust, by calculating the change slope at \pm 1 pooled SD from the midpoint, using procedures for testing linear combinations of regression coefficients (Cohen \& Cohen, 1983; Edwards $\&$ Parry, 1993). These estimates, together with the estimates of the stability slope, then captured the instantaneous effect of trust on leader effectiveness for the hypothetical groups that experienced an increase or decrease in trust, or, alternatively, stable levels of trust across time periods (respectively). These three estimates were then used as alpha paths for the subsequent mediation analysis. The beta path was calculated as the effect of leader effectiveness on squad performance, controlling for the polynomial regression terms of trust. This results in three indirect effects estimates, reflecting increasing, stable, and decreasing trust.

Finally, to estimate the effects of expectations and transformational leadership on the starting levels and change in trust (Hypotheses 3 and 4), we fit a growth model (across all available time points) in which a linear and non-linear index of time periods predicted the effects of trust for a given squad; these indicators were modeled as random effects. These random effects (as well as the random intercept) were then allowed to be predicted by expectations and manifested leader behaviors (as cross-level moderators). To ensure that these models were robust, we also reran them utilizing related growth approaches (listed in the Appendix).

\section{Hypothesis Tests}

Table 1 shows means, standard deviations, and intercorrelations among the variables in our study. Our first set of hypotheses considered the effects of trust change and stability on perceptions of leadership effectiveness. In terms of the effects of stable trust, results of a polynomial model (summarized in Table 2) indicated that leaders who had high, and stable, levels of trust were seen as more effective by their subordinates, compared to leaders who had low and stable levels of trust (stability slope estimate $=0.54, p<0.01$ ). Leaders that experienced a positive change in trust were regarded as more effective. Specifically, those who managed to increase their followers trust in them rather than those who experienced a decline in the same, as evidenced by a positive change curve coupled with a positive change slope (change curve estimate $=0.52, p<0.05$; change slope estimate $=0.30, p<0.05)$. A graphical representation of these effects can be seen in Fig. 2. In this figure, the dashed line on the graph floor represents the change slope, while the solid line represents the stability slope. The graph floor shows areas of equivalence represented by the colored curved lines to illustrate where patterns of trust change produce equivalent leadership effectiveness reports.

Figure 2 shows the effects of stable versus changing trust in the curvature on the surface above the dashed line; as the surface curves upwards, we can initially conclude that changes in trust are associated with greater levels of leader effectiveness compared to stability in the same. Moreover, the right part of the surface is tilted upwards relative to the left, indicating that increases in trust are associated with higher levels of leadership effectiveness. Taken together, the surface characteristics indicate that, for a given level of trust 
Table 2 Path model, response surface characteristics, and indirect effects

\begin{tabular}{|c|c|c|c|c|}
\hline & \multicolumn{2}{|c|}{ Leader effectiveness } & \multicolumn{2}{|c|}{ Group performance } \\
\hline & $\gamma$ & $t$-value & $\gamma$ & $t$-value \\
\hline \multicolumn{5}{|l|}{ Variables } \\
\hline \multicolumn{5}{|l|}{ Controls } \\
\hline Average team gender & $0.45^{*}$ & 2.10 & $-0.41 * *$ & -4.26 \\
\hline Average team GPA & 0.02 & 0.53 & 0.06 & 1.24 \\
\hline Average team age & $0.00^{*}$ & 2.23 & 0.00 & -0.57 \\
\hline \multicolumn{5}{|l|}{ Starting and ending trust } \\
\hline $\mathrm{T} 1$ trust & 0.12 & 1.20 & -1.06 & -1.42 \\
\hline $\mathrm{T} 2$ trust & $0.42^{* *}$ & 5.95 & 0.35 & 1.01 \\
\hline $\mathrm{T} 1$ trust squared & 0.06 & 0.48 & $-0.49 *$ & -2.01 \\
\hline $\mathrm{T} 1 / \mathrm{T} 2$ trust interaction & $-0.26^{\dagger}$ & -1.74 & 0.13 & 0.60 \\
\hline $\mathrm{T} 2$ trust squared & $0.21^{* *}$ & 3.43 & -0.09 & -0.99 \\
\hline \multicolumn{5}{|l|}{ Mediator } \\
\hline \multirow[t]{2}{*}{ Leader effectiveness } & & & $0.26 * *$ & 3.24 \\
\hline & \multicolumn{2}{|c|}{ Estimate } & & $t$-value \\
\hline \multicolumn{5}{|c|}{ Response surface characteristics } \\
\hline Stability slope & \multicolumn{2}{|c|}{$0.54 * *$} & & 5.57 \\
\hline Change slope & \multicolumn{2}{|c|}{$0.30 *$} & & 2.05 \\
\hline Stability curve & \multicolumn{2}{|c|}{0.01} & & 0.07 \\
\hline \multirow[t]{2}{*}{ Change curve } & \multicolumn{2}{|c|}{$0.52 *$} & & 2.11 \\
\hline & Estimate & $t$-value & $L L$ & $U L$ \\
\hline \multicolumn{5}{|c|}{ Indirect effects through leader effectiveness } \\
\hline Stable trust & 0.14 & 2.55 & 0.03 & 0.25 \\
\hline Increasing trust & 0.35 & 2.05 & 0.02 & 0.68 \\
\hline Decreasing trust & -0.19 & -1.29 & -0.49 & 0.10 \\
\hline
\end{tabular}

$N=111$ observations nested within 41 raters for team ratings; $N=96$ observations nested within 35 raters for superior leader reports. All coefficients and derived estimates unstandardized. LL and UL refer to the lower and upper levels of a 95\% confidence interval, respectively

$* p<0.05$

$* * p<0.01$

across two periods, increases in trust are associated with higher levels of leader effectiveness compared to stable or decreasing trust. In addition, and as expected, stable trust at a high level is associated with greater levels of leader effectiveness compared to stable trust at a low level. Based on a joint consideration of the change curve and slope estimates, changes in trust are associated with higher levels of effectiveness compared to stability, with these results being driven by increases in trust (rather than decreases). Hypothesis 1 is supported.

We also examined the indirect effects of trust across time periods on squad effectiveness through leader effectiveness for groups that had increasing, stable or decreasing levels of trust in their leader. Table 2 also summarizes these effects. There was a significant indirect effect from trust to leader effectiveness to squad effectiveness for groups that experienced stable levels of trust ( $\mathrm{IE}=0.14, p<0.05 ; \mathrm{CI}_{95 \%}=0.03$, 0.25 ), as well as for groups that experienced increases in trust over time $\left(\mathrm{IE}=0.35, p<0.05 ; \mathrm{CI}_{95 \%}=0.02,0.68\right)$. However, groups that experienced declines in trust demonstrated an indirect effect no different from zero (IE $=-0.19$, $\left.p=\mathrm{ns} ; \mathrm{CI}_{95 \%}=-0.49,0.10\right)$. Hypothesis 2 was thus supported for increasing and stable trust groups.

Table 3 presents the models predicting starting values of trust, as well as linear and non-linear trust growth as predicted by expectations and transformational leadership behavior. Exemplar leader trajectories predicted from the data are shown in Fig. 3. These cases illustrate variations from the sample of leaders who experienced increases, stability, or decreases in trust.

In terms of trust development over time, expectations had a negative effect on the linear rate of change in trust (linear $\gamma=-0.68, p<0.05)$. Leaders one standard deviation above the mean on expectations experienced a decline in trust on behalf of their followers over time (slope $=-0.33, p<0.05$ ), while those leaders one standard deviation below the mean 


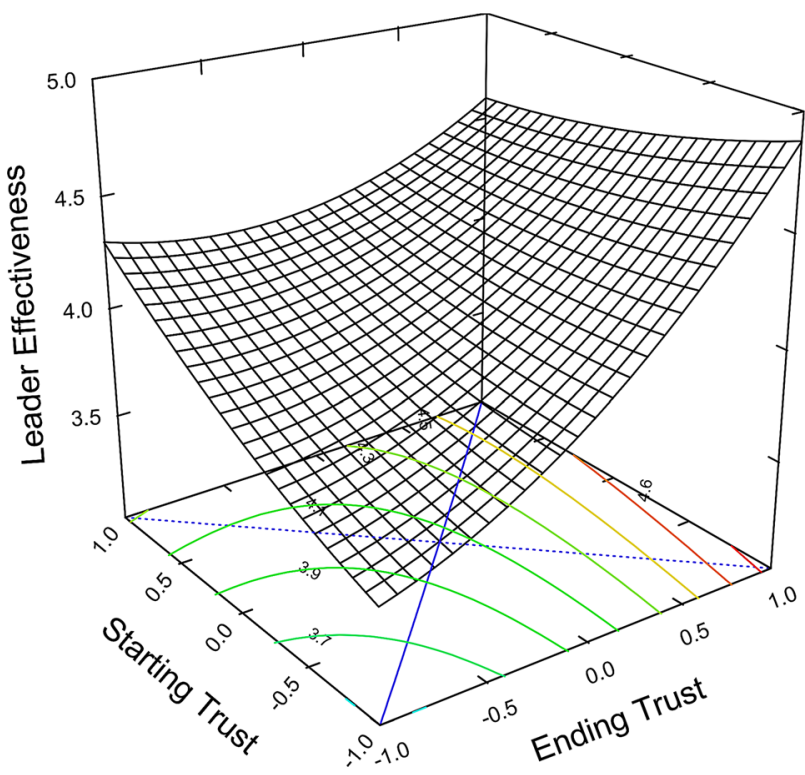

Fig. 2 Graphic representation of the effects of trust stability and change on leader effectiveness. Starting Trust refers to Trust at T1; Ending Trust refers to Trust at T2

experienced an increase in the same (slope $=0.45, p<0.05$ ). Figure 4 depicts this effect.

Similarly, transformational leadership had a positive effect on the linear rate of change in trust (linear $\gamma=0.68$, $p<0.01$ ). Leaders one standard deviation above the mean on transformational leadership behaviors experienced an increase in trust from followers over time (slope $=0.48$, $p<0.01$ ), while those leaders one standard deviation below the mean experienced a decrease in the same (slope $=-0.37$, $p<0.05)$. See Fig. $5 .^{5}$

Overall then, leaders who started off with high expectations were likely to experience a drop in how much their subordinates trusted them over time, with the opposite being true for leaders who started off with low expectations. Conversely, high levels of transformational leadership were associated with increases in subordinates' trust of the leader over time, while low levels of transformational leadership were associated with decreases in subordinates' trust of the leader over time. These results indicate support for Hypotheses 3 and 4.

\footnotetext{
5 The curvilinear change in trust over time was not significantly predicted by expectations (non-linear $\gamma=0.10, p<0.10$ ), but was predicted by transformational leadership (non-linear $\gamma=-0.13, p<0.01$ ), but the actual rate of change at one standard deviation above and below the mean for expectations and transformational leadership was only significant for those above the mean in the latter (curve $=-0.09$, $p<0.01$ ), and that effect was relatively trivial. Rerunning the model without the curvilinear component resulted in no changes in coefficient sign or significance.
}

Table 3 Effects of expectations and transformational leadership on trust level and change over time

\begin{tabular}{|c|c|c|c|c|}
\hline & \multicolumn{2}{|c|}{ Model 1} & \multicolumn{2}{|l|}{ Model 2} \\
\hline & $\gamma$ & t-ratio & $\gamma$ & t-ratio \\
\hline \multicolumn{5}{|l|}{ Coefficients } \\
\hline Intercept & 5.92 & 62.87 & 6.08 & 58.47 \\
\hline Slope & 0.12 & 1.35 & 0.06 & 0.53 \\
\hline Curve & -0.02 & -1.14 & -0.01 & -0.56 \\
\hline \multicolumn{5}{|l|}{ Intercept effects } \\
\hline Average team gender & & & -0.25 & -0.50 \\
\hline Average team GPA rank & & & 0.00 & 0.05 \\
\hline Average team age & & & 0.12 & 1.18 \\
\hline Average team agreeableness & & & 0.56 & 1.90 \\
\hline Initial expectations & & & $1.04 * *$ & 3.32 \\
\hline Transformational leadership & & & -0.32 & -1.44 \\
\hline \multicolumn{5}{|l|}{ Slope effects } \\
\hline Average team gender & & & 0.32 & 0.64 \\
\hline Average team GPA rank & & & 0.00 & -0.14 \\
\hline Average team age & & & -0.13 & -1.18 \\
\hline Average team agreeableness & & & -0.40 & -1.36 \\
\hline Initial expectations & & & $-0.68 *$ & -2.47 \\
\hline Transformational leadership & & & $0.68 * *$ & 3.16 \\
\hline \multicolumn{5}{|l|}{ Curve effects } \\
\hline Average team gender & & & -0.07 & -0.74 \\
\hline Average team GPA rank & & & 0.00 & 0.31 \\
\hline Average team age & & & 0.02 & 0.94 \\
\hline Average team agreeableness & & & 0.05 & 0.90 \\
\hline Initial expectations & & & 0.10 & 1.86 \\
\hline Transformational leadership & & & $-0.13 * *$ & -2.89 \\
\hline
\end{tabular}

$N=444$ observations derived across 4 time points from 111 leaders. All coefficients unstandardized

$* p<0.05$

$* * p<0.01$

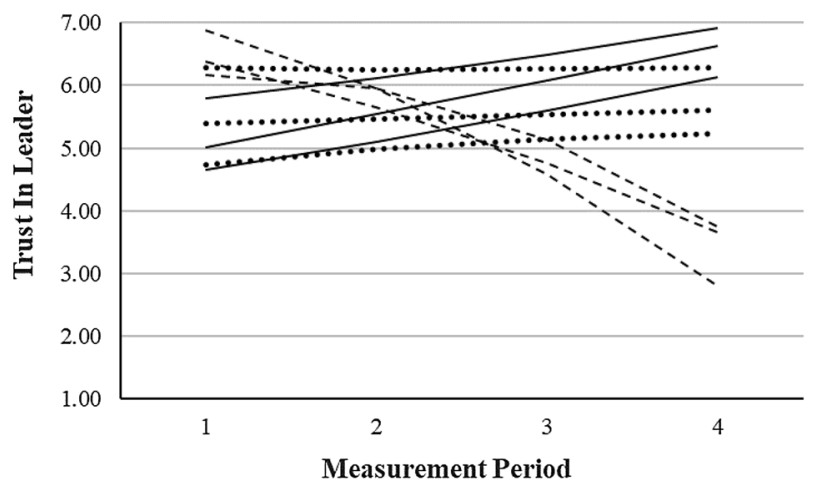

Fig. 3 Exemplar leaders exhibiting increase (Solid Lines), stability (Dotted Line), and decrease (Dashed Line) in trust over time 


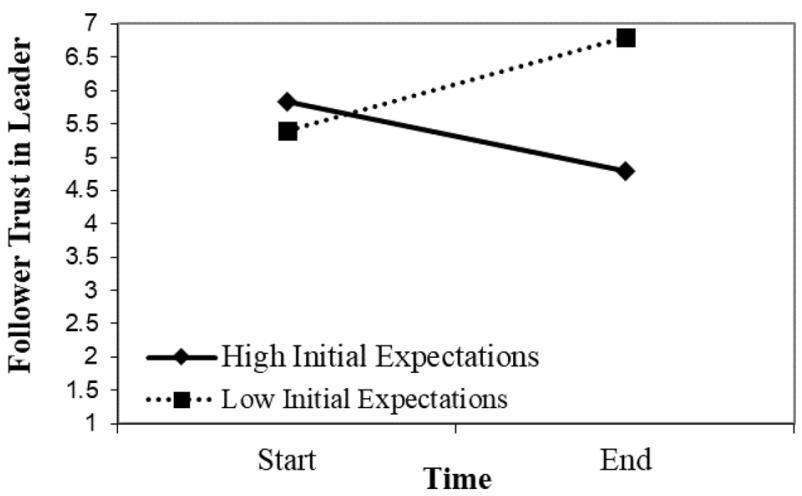

Fig. 4 Trust in leader across time and expectations

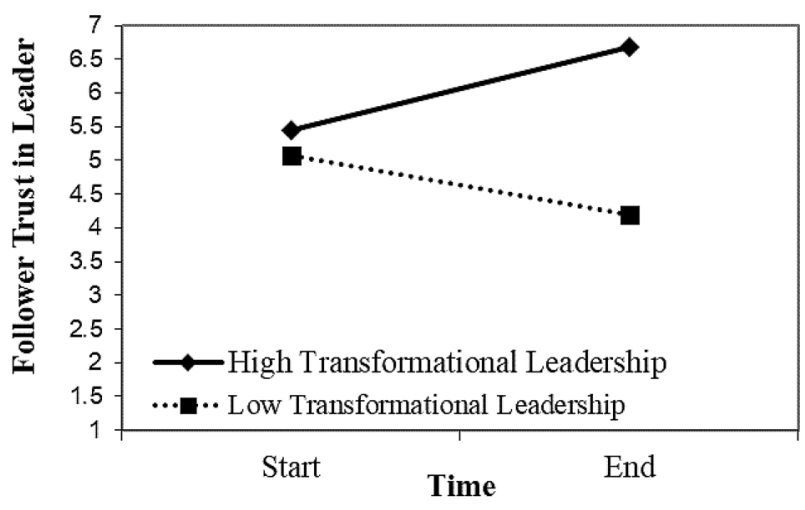

Fig. 5 Trust in leader across time and transformational leadership

These additive effects indicate, for example, that leaders who begin with high expectations are able to maintain a high level of trust on behalf of their subordinates toward them if they display high levels of transformational leadership. Leaders who begin with low expectations are able to quickly overcome the initial trust deficit through a more rapid increase in trust from their followers if they display high levels of transformational leadership. Conversely, leaders who begin with low expectations struggle to gain the trust of their followers if they display low levels of transformational leadership. And leaders who begin with high expectations experience a sharp negative rate of change in their followers' trust in them if they display low levels of transformational leadership.

Outside of hypothesized effects, the data showed several other expected patterns. Expectations were associated with a higher level of initial trust of followers toward the leader (intercept $\gamma=1.04, p<0.01$ ), but transformational leadership behavior was not $(\gamma=-0.32, p>0.10)$. As expected, average team agreeableness was associated with high initial expectations of the leader $(\gamma=0.55, p<0.01)$. Thus, the group's initial expectations of its leader are a function of their overall agreeableness.

\section{Additional Analyses and Robustness Checks}

We wanted to ensure that our results were not due to mere regression to the mean, and that they were not subject to ceiling or floor effects. To address this, we investigated the covariance between the random effect representing the intercept, linear, and non-linear growth effects. The covariance between the intercept and linear term was non-significant ( $\operatorname{cov}=-0.22, p=0.84)$, as was the covariance between the linear and non-linear terms (cov $=-0.05, p=0.72)$. Finally, the covariance between the non-linear term and intercept was also non-significant ( $\operatorname{cov}=0.04, p=0.83)$. Taken together, these results indicate that simple initial levels of trust are not, by themselves, associated with future improvement or deterioration or changes in the rate of the same, and that trust development does not slow or accelerate based on overall trajectories. These effects assuage possible concerns about regression to the mean, ceiling, and floor effects.

Furthermore, we replicated these analyses using different time points as the source for starting and ending levels of trust, comparing trust levels from Time 1 to Time 3 and from Time 2 to Time 3, in order to ensure the robustness of our results and their sensitivity to the choice of comparisons. In all these analyses, our results were consistent and the conclusions unchanged ${ }^{6}$ (see Appendix B, Table 4 for a summary of these results). Overall, the data indicated that the highest levels of effectiveness were associated with leaders who exhibited an increase in the extent to which their followers trusted them, followed by those leaders that had high and stable levels of trust over time. Leaders who experienced a drop in how much their followers trusted them were seen as less effective than the two categories above, and were only seen as more effective than those leaders that had low, and stable, levels of trust from their followers throughout the study. This indicates a higher level of robustness in our findings, compared to a single pair of comparisons, and thus increases our confidence in our results.

Finally, we wanted to ensure that the results were not unique to the method we utilized. As a result, we reran the analyses using, instead of the polynomial approach, a latent growth model with fixed effects, a latent growth model with random effects, and a latent change model. Table 5 in the Appendix B summarizes these analyses. In these models, we first predicted the effects of transformational leadership and initial expectations on starting trust values. Both of these variables were positively associated with initial levels of trust (with coefficients ranging from 0.35 to 0.46 for initial

\footnotetext{
${ }^{6}$ We replicated the baseline analyses utilizing leadership effectiveness ratings reported by the focal leader's superior, instead of by squad members; these results also produced very similar results, with an exception of a non-significant change slope.
} 
expectations and from 0.27 to 0.40 for transformational leadership across models; $p<0.01$ in all cases). We then examined the effect of initial expectations and transformational leadership on the growth of (or change) in trust over time. As expected, initial expectations were negatively associated with the rate of change in trust over time (coefficients ranging from -0.22 to $-0.28, p<0.01$ in all cases), while transformational leadership was associated with an increase in the same (coefficients ranging from 0.12 to $0.17 ; p<0.01$ in all cases). Finally, both starting levels of trust in leader as well as growth in trust in leader over time were associated with leadership effectiveness across all three models (with coefficients for the effects of intercept ranging from 2.28 to 2.65 and the coefficients for the effects of growth or change ranging from 3.61 to $4.18 ; p<0.05$ in all cases). Overall then, these alternative analyses provide a very similar conclusion relative to our own; expectations are associated with initial values of trust in leader (positively), and with growth (or decrease) of trust in leader over time (expectations negatively, TL positively). While these alternative models have more stringent assumptions (such as a symmetric effect for trust increases or decreases on leadership effectiveness), the fact that these point to the same conclusion again increases the confidence in our results.

\section{Discussion}

Leaders and leadership researchers have long operated on the notion that developing a high level of trust is critical for effectiveness (Dirks \& Ferrin, 2002; Hoch et al., 2018). The present study builds on this stream of work by considering the role and implications of how trust changes for new leaders. Trust is critical for leaders as they start new roles, and it is particularly susceptible to change during that time period. Indeed, as illustrated in Fig. 3, leaders can experience increases, decreases, or neither in how much their followers trust them over their first months. The gap in past research stems from the fact that while trust is inherently dynamic, and there have been repeated calls over the past two decades for empirical research, such research has rarely been conducted. Below we describe some of the specific contributions and insights from our study.

\section{Insights for Research}

Our first contribution involves the effect of follower trust on leader effectiveness. Existing research has frequently documented that the level of trust in a leader is associated with performance of individuals and groups (Dirks, 2000; Dirks \& Ferrin, 2002). Drescher et al. (2014) found that change in trust is associated with change in team performance. The present study went beyond these known effects by demonstrating that the change in trust in the leader, above and beyond level of trust, impacts the level of performance outcomes. The plot in Fig. 2 provides a detailed view of this relationship for leader effectiveness. This sample, which started at a low to moderate level of followers' trust in their leaders that increased over time, produced a level of leader effectiveness slightly higher than starting high with no change. This is a new insight which has not previously been documented in empirical research.

This finding is important for several reasons. First, it departs from the conventional wisdom which seeks to maximize the level of trust in the leader from day 1 . According to our findings, although having a high level of follower trust in a leader is associated with effectiveness, it is even more effective to start at a moderate level of trust and increase to a high level over the first several months. Although the difference in effectiveness is only marginally higher, this approach has the substantial advantage for leaders of avoiding the tendency to experience a drop in trust that can occur when they enter roles with high expectations from employees. This finding underscores that to fully understand how trust impacts outcomes, one needs to take into account not just the level of trust at a given point in time, but also the pattern of how trust has developed over time, which suggests the need for more longitudinal research designs.

This finding is also important because it suggests that leaders who start with lower expectations, perhaps because they come from particular demographic backgrounds (minorities, individuals who are not match leader prototypes, and so on), or because they come in without a reputation, can build their followers' trust in them and be effective. Indeed, they actually have greater potential to be effective than leaders who start out with high expectations. Future research may examine this dynamic for leaders who are demographic minorities.

For future research, one question is whether the findings would be replicated for leaders who are long tenured. Theoretically, the effect of change in follower trust for an established leader should operate the same; a change in follower trust for an established leader would be very salient and thus would presumably have a strong effect. In conducting this type of study, researchers would need to carefully consider the appropriate point for the first measurement of trust. Our study had a natural starting point. Past research on trust in leaders has tended to measure trust at a point in time driven by necessity or convenience of sample availability.

Our second contribution involves the antecedents of trust. Over two decades ago, McKnight et al. (1998) highlighted the importance of initial trust, as well as implications for how it would impact subsequent trust. As they observed, due to workplace trends, it is common to work with individuals whom you do not know, but must nevertheless rely upon. Although this trend has accelerated, empirical research has 
not followed up on these ideas to study the initial level of trust for leaders and how trust changes in the first months. Our paper is among the first study to do so.

One finding from our study is that expectations, which are positively associated with initial trust in the leader, are negatively correlated with the subsequent direction and rate of change in trust. This is not just a regression to the mean phenomenon but rather is based on psychological factors. For example, high expectations that are not based on experience, but based on unreliable factors, are likely to be unfulfilled. When it comes to trust, single incidents of violated expectations can have a significant impact. Furthermore, the data suggest that the higher the starting level, the greater the rate of decrease. This finding is important because common wisdom would suggest that leaders seeking to establish a good first impression start with high initial levels of followers' trust in them; however, our data suggest that in doing so they increase the likelihood of a subsequent loss of follower trust. Fortunately, leaders can engage in transformational leader behaviors to avoid this fate. A reviewer observed that these findings also suggest that the role of initial trust may be more complex than has been previously assumed. Robinson's (1996) foundational study on trust and psychological contracts demonstrated that high initial trust will buffer people from experiencing subsequent violations. The present study suggests that this may not always be the case, and that high initial trust can deteriorate and become detrimental to leader and team performance.

Existing research has long shown a positive correlations between transformational leadership and trust (Dirks \& Ferrin, 2002). Our study provides greater clarity into the nature of that relationship, with results demonstrating how transformational leadership behaviors accelerated the development of followers' trust for new leaders. Leaders who started with low or moderate expectations built their followers' trust more rapidly proportionally to the rate at which they engaged in that set of behaviors. Leaders who started with high expectations, were able to maintain high followers' trust by engaging in transformational leadership behaviors. Leaders who did not engage in those behaviors rapidly lost their followers' trust (see Fig. 3). Theoretical models for the development of trust may need to consider adding transformational leadership behaviors as an important antecedent and also rate of change of trust over time. Future research might explore the importance of each category of transformational leadership behaviors over time.

The results of the study contribute to the ethics literature by revealing evidence that transformational leadership, an ethics-based leadership style, accelerates the development of trust between leaders and followers in new relationships. Previous research in the ethics literature found that leaders' ethical behavior was positively related to followers' trust (Palanski et al., 2011; Su, 2014). The findings from this study provide more clarity on the relationship between leaders' ethical behavior and followers' trust. Results suggest that leaders' ethical behavior, part of idealized influence, combined with the other three categories of transformational leadership (individual consideration, inspirational motivation, and intellectual stimulation), accelerate the change in trust in new relationships. Other ethics-based leadership styles such as servant, ethical, and authentic leadership are also positively related to trust in leaders and organizations (Bedi et al., 2016; Parris \& Peachey, 2013; Peus et al., 2012; $\mathrm{Xu}$ et al., 2016). Our finding suggests that there are some unique aspects of transformational leadership that can produce the acceleration of trust that may not be present in these other leadership styles (e.g., impact multiple factors of trustworthiness, including care), but that could be verified in future research.

A final contribution, partially noted above, is to spotlight a critical time period of trust between leaders and employees. For the most part, research on trust has not considered its role at different periods. One of the periods in which trust may be particularly critical, and particularly changeable, is during a leadership transition. When a new leader takes over, employees actively seek to understand the implications for their own work and career and information they receive is new. Our study was not able to identify the exact length of time which is most critical for changing trust; future research might explore whether it is only the first 3 months, or whether the period is longer. The theory would also presumably apply to other critical periods where employees feel an intense sense of vulnerability, such as during mergers.

\section{Insights for Leaders}

When leaders enters a new position or organization, how can they quickly develop their followers' trust in them? How does the change in followers' trust impact outcomes? Our study provides some answers to these important practical questions. This study suggests that leaders may establish trust most quickly by managing expectations for how they will be an effective leader and a positive influence on employees. Research on leader prototypes provides some insight into how leaders can do this through words, body language, dress, and so on. Results from this study suggest that the common prototype of an effective leader, in this population, embodies the characteristics of a transformational leader. It seems that leaders who exhibit this style in the beginning of the leader-follower relationships generate higher positive expectations in their followers, which leads to higher levels of initial followers' trust. The results also suggest that leaders can maintain high levels of initial followers' trust or, alternatively, build and maintain trust over time via transformational leadership behaviors. 
This insight leads to the second question: What pattern of trust in leader development is best for a leader's performance? As noted above, the fastest way to establish trust is by starting high. Similarly, conventional wisdom would suggest that it is optimal to start with a good first impression and a high level of trust. Our analysis, however, suggests that starting high has the pitfall of being more likely to experience a drop in follower trust unless the leader engages in transformational leadership behaviors. In addition, our results suggest leader effectiveness and unit effectiveness is generally highest when the leader starts with a low or moderate level of follower trust and then builds it over time. The results indicate it is important in the beginning of the leader-follower relationship for leaders to purposefully help shape followers' accurate expectations of them. Leaders can do this by understanding their unique leadership style and sharing this with followers both orally and in writing. After sharing their leadership approach with followers, leaders need to strive each day to act consistently with their espoused leadership philosophy (also see Vogelgesang et al., 2021). Leaders taking charge of a new team or organization should meet with followers to discuss mutual expectations. This initial meeting provides leaders the venue to shape realistic followers' expectations and at the same time communicate their expectations of followers. By intentionally shaping followers' expectations of them, leaders may avoid a drop in followers' trust because they have helped set followers' expectations to a more accurate initial level of trust.

\section{Limitations}

Several aspects of the study design warrant consideration as limitations. A first consideration is the nature of the relationships we examined. Our study focused on leader-employee relationships from inception of a relationship to 3 months. Given the design and focus, the study's conclusions are best for understanding how a leader enters a new position and how the level of trust changes over the course of the initial months. Some conceptual work has considered whether the dynamics will change depending upon whether the relationship in the formation stage versus the dissolution stage (e.g., Fulmer \& Gelfand, 2013). Our data are not well suited for testing these ideas.

Given the defined length of the relationship, the study was unable to track follower trust in leader over a longer period, such as multiple years. This may have two implications which could be explored in future research. One implication is that the changes in follower trust become smaller over time as judgments get frozen, or they reach a ceiling or floor. A second potential implication is that, as the length of the relationship changes over time, the relationships between constructs may change. For example, Palmatier et al. (2013) found that the impact of trust can change over a very long period of time. In their study of buyer-supplier relationships, at approximately the 6-year point, the impact of trust on commitment decreased and was supplanted by a stronger effect of bilateral investments. A similar dynamic may occur in interpersonal relationships over an extended period of time, as norms take over or as the parties make significant investments in the relationship which create commitment. On the other hand, the effect of a change in trust may be very salient in an established relationship and thus have a major impact.

A second consideration of our study's design is that we intentionally chose a unique context which allowed us to rule out many other factors which may determine trust. This context included the fact that there was limited reputational information about the leader available, as may be in the case in other instances. This may impact the initial level of trust, but we do not expect it to have other major impacts.

A third part of the design involved the measurement of variables. The data for follower trust in leaders, initial expectations, transformational leadership, and leader effectiveness were collected from squad members (subordinates) and data on squad performance were gathered from platoon leaders (the leaders' supervisors). One question may be whether the conclusions are biased by common method variance. There are several factors that we believe allay concerns. One factor is the difference in time collection for the different variables: initial expectations was collected at Time 1, transformational leadership was collected at Time 2, leader effectiveness was collected at Time 3 , and trust involved the change over time. This type of design tends to substantially reduce problems associated with common method variance (Spector, 2006). A second factor is the analysis used to test the hypotheses. The statistical procedure to test our model used a polynomial regression model, with interactions between of the focal variables and time. Siemsen, Roth, and Oliveira (2009) demonstrated that interaction and quadratic effects cannot be artifacts of common method variance (although results can sometimes be deflated). The third factor is that the measure of unit performance, our final dependent variable, was collected from platoon leaders. Finally, results were robust to choice of comparison time period, as well as to the source of the mediating variable. Together, these factors allay concerns that the results of the study are an artifact of common method variance. 


\section{Conclusion}

The present study considered a frequently experienced and important issue for leaders: when leaders enter into a new role, they seek to develop trust from their group. This required a longitudinal and dynamic approach which had been called for in prior work, but has been rarely used. Investigating the pattern of development of trust over time, provides researchers with greater insights into the dynamic nature of trust and its influence on leadership and effectiveness, and suggests alternative strategies for leaders who are starting a new role.

\section{Appendix A}

\section{Measures Used in the Study}

\section{Initial Expectation of Leader Items}

1. I expect to like my squad leader.

2. I expect that my squad leader will contribute to my development.

3. I expect my squad leader to be an effective leader.

4. My squad leader appears to be a leader I want to become.

\section{Trust Items}

1. I can depend on my squad leader to meet his/her responsibilities.

2. My squad leader follows through with commitments he/ she makes.

3. I see no reason to doubt the competence of my squad leader.
4. My squad leader approaches tasks with professionalism and dedication.

5. I feel confident that my squad leader will always care about my personal needs in the squad setting.

6. If I share a problem with my squad leader, I know he/she will respond constructively and caringly.

7. I can talk freely with my squad leader about difficulties I am having, and he/she will listen.

8. My squad leader cares about my success as a cadet.

\section{Leader Performance Assessment Items}

1. Led by example.

2. Built positive relationships within the squad.

3. Created a positive, open environment within the squad.

4. Positively impacted my development as a cadet.

5. Exercised leadership that was instrumental in the squad achieving all assigned objects (i.e., got results).

6. Performed his/her duties in a manner that ensured the squad was successful.

\section{Squad Performance Measures}

1. Met or exceeded standards on all assigned tasks (i.e., got results).

2. Exhibited good teamwork with other squads within the platoon.

3. Worked together to enhance each member's development.

\section{Appendix B}

\section{Additional Analyses}

See Tables 4, 5, 6, 7 . 
Table 4 Comparing baseline to alternative time frame comparisons

\begin{tabular}{|c|c|c|c|c|c|c|}
\hline & \multicolumn{2}{|c|}{ Baseline comparison } & \multicolumn{2}{|c|}{ Alternative comparison \#1 } & \multicolumn{2}{|c|}{ Alternative comparison \#2 } \\
\hline & $\gamma$ & $t$-value & $\gamma$ & $t$-value & $\gamma$ & $t$-value \\
\hline \multicolumn{7}{|l|}{ Variables } \\
\hline Average team Gender & $0.46^{*}$ & 2.10 & 0.19 & 1.75 & 0.18 & 1.48 \\
\hline Average team GPA & 0.03 & 0.55 & 0.04 & 1.71 & 0.04 & 1.61 \\
\hline Average team Age & $0.00 *$ & 2.23 & 0.00 & 0.51 & 0.00 & 0.59 \\
\hline Starting trust & 0.13 & 1.31 & $0.22 * *$ & 3.45 & $0.15^{* *}$ & 3.09 \\
\hline Ending trust & $0.42 * *$ & 5.98 & $0.80 * *$ & 10.39 & $0.76^{* *}$ & 9.28 \\
\hline Starting trust squared & 0.07 & 0.52 & 0.11 & 1.08 & $0.10 *$ & 2.33 \\
\hline Starting/ending interaction & $-0.27^{\dagger}$ & -1.85 & $-0.18 \dagger$ & -1.93 & $-0.17 *$ & -2.38 \\
\hline \multirow[t]{2}{*}{ Ending trust squared } & $0.21 *$ & 3.45 & 0.04 & 0.95 & $0.09^{*}$ & 1.99 \\
\hline & Estimate & $t$-value & Estimate & $t$-value & Estimate & $t$-value \\
\hline \multicolumn{7}{|l|}{ Response surface characteristics } \\
\hline Stability slope & $0.55^{* *}$ & 5.64 & $1.02 * *$ & 13.29 & $0.90 * *$ & 11.43 \\
\hline Change slope & $0.29 *$ & 2.03 & $0.58 * *$ & 4.90 & $0.61 * *$ & 5.71 \\
\hline Stability curve & 0.01 & 0.03 & -0.03 & -0.24 & 0.03 & 0.36 \\
\hline Change curve & $0.54 *$ & 2.21 & $0.34 *$ & 2.20 & $0.36 * *$ & 3.37 \\
\hline
\end{tabular}

$N=111$ observations nested within 41 raters for team ratings; $N=96$ observations nested within 35 raters for superior leader reports. All coefficients and derived estimates unstandardized. Baseline comparisons involve T1 (starting) to T2 (ending) trust levels; alternative comparisons \#1 involve T1 (starting) to T3 (ending) trust levels; alternative comparisons \#2 involve T2 (starting) to T3 (ending) trust levels

$* p<0.05$

$* * p<0.01$

Table 5 Latent growth/change re-analysis

\begin{tabular}{|c|c|c|c|c|c|c|}
\hline & \multicolumn{2}{|c|}{$\begin{array}{l}\text { M1: LGM, fixed } \\
\text { effects }\end{array}$} & \multicolumn{2}{|c|}{$\begin{array}{l}\text { M2: LGM, random } \\
\text { effects }\end{array}$} & \multicolumn{2}{|l|}{ M3: LCM } \\
\hline & $b$ & $t$-value & $b$ & $t$-value & $b$ & $t$-value \\
\hline \multicolumn{7}{|l|}{ Effects on starting value } \\
\hline Gender & 0.07 & 0.72 & 0.09 & 1.02 & 0.08 & 0.86 \\
\hline Age & 0.02 & 0.59 & 0.01 & 0.43 & 0.00 & -0.05 \\
\hline GPA & 0.00 & 0.40 & 0.00 & 0.29 & 0.00 & 0.02 \\
\hline Initial expectations & $0.45^{* *}$ & 5.98 & $0.46^{* *}$ & 6.20 & $0.35 * *$ & 5.12 \\
\hline Transformational leadership & $0.28 * *$ & 3.68 & $0.27 * *$ & 3.69 & $0.40 * *$ & 6.15 \\
\hline \multicolumn{7}{|l|}{ Effects on growth/change } \\
\hline Gender & 0.02 & 0.27 & -0.02 & -0.27 & -0.04 & -0.69 \\
\hline Age & -0.01 & -0.32 & 0.03 & 1.61 & $0.03 *$ & 2.03 \\
\hline GPA & $0.00 * *$ & 2.63 & $0.00 * *$ & 2.92 & $0.00 *$ & 2.40 \\
\hline Initial expectations & $-0.28 * *$ & -6.20 & $-0.28 * *$ & -6.27 & $-0.22 * *$ & -5.15 \\
\hline Transformational leadership & $0.15^{* *}$ & 3.40 & $0.17 * *$ & 4.03 & $0.12 * *$ & 2.90 \\
\hline \multicolumn{7}{|l|}{ Effects on leadership effectiveness } \\
\hline Gender & 0.01 & 0.04 & -0.01 & -0.06 & 0.19 & 1.01 \\
\hline Age & 0.02 & 0.31 & -0.02 & -0.26 & -0.03 & -0.44 \\
\hline GPA & 0.00 & -0.89 & 0.00 & -0.74 & 0.00 & -0.41 \\
\hline Initial expectations & -0.08 & -0.17 & -0.19 & -0.24 & 0.12 & 0.51 \\
\hline Transformational leadership & -0.68 & -1.50 & -0.64 & -1.51 & -0.73 & -1.29 \\
\hline Starting value & $2.65 * *$ & 2.86 & $2.65^{*}$ & 2.26 & $2.28 * *$ & 2.66 \\
\hline Growth/change & $3.99 *$ & 2.46 & $3.61 *$ & 2.17 & $4.18^{*}$ & 2.23 \\
\hline
\end{tabular}

LGM latent growth model, $L C M$ latent change model. 
Table 6 Effects of change in trust model omitting controls

\begin{tabular}{lcrrrrr}
\hline & \multicolumn{2}{l}{$\begin{array}{l}\text { Leader Effective- } \\
\text { ness }\end{array}$} & & \multicolumn{2}{l}{$\begin{array}{l}\text { Group Perfor- } \\
\text { mance }\end{array}$} \\
\cline { 2 - 3 } \cline { 6 - 7 } & $\gamma$ & t-value & & & t-value \\
\hline Variables & & & & & \\
Starting and ending trust & & & & & \\
$\quad$ Starting trust & 0.19 & 1.83 & & 0.07 & 0.39 \\
Ending trust & $0.43^{* *}$ & 5.51 & & 0.05 & 0.44 \\
Starting trust squared & 0.15 & 1.49 & -0.33 & -1.65 \\
Starting/ending interaction & -0.22 & -1.95 & 0.01 & 0.06 \\
$\quad$ Ending trust squared & $0.22^{* *}$ & 3.71 & -0.09 & -0.97 \\
Mediator & & & & & \\
$\quad$ Leader effectiveness & & & $0.27^{* *}$ & 2.77 \\
\hline
\end{tabular}

$N=111$ observations nested within 41 raters for team ratings; $N=96$ observations nested within 35 raters for superior leader reports. All coefficients unstandardized

$* p<0.05$

$* * p<0.01$

Table 7 Predicting change in trust model omitting controls

\begin{tabular}{lcr}
\hline & Model 2 & \\
\cline { 2 - 3 } & $\gamma$ & t-ratio \\
\hline Coefficients & 5.99 & \\
Intercept & 0.09 & 70.83 \\
Slope & -0.02 & 1.07 \\
Curve & & -0.93 \\
Intercept effects & $0.91^{* *}$ & \\
Initial expectations & -0.03 & -0.15 \\
Transformational leadership & & \\
Slope effects & $-0.46^{*}$ & -2.08 \\
Initial expectations & $0.47^{*}$ & 2.52 \\
Transformational leadership & & \\
Curve effects & 0.06 & -2.53 \\
$\quad$ Initial expectations & $-0.09^{*}$ & \\
Transformational leadership & & \\
\hline
\end{tabular}

$N=444$ observations derived across 4 time points from 111 leaders. All coefficients unstandardized

$* p<0.05$

$* * p<0.01$

Acknowledgements We thank Sean Hannah, Andrew Knight, and the organizational behavior research group at Washington University for their comments and suggestions. The opinions expressed in this article are the authors' own and do not reflect the view of the United States Military Academy, the United States Army, or the Department of Defense.

\section{Declarations}

Conflict of interest The authors have no relevant financial or non-financial interests to disclose.

\section{References}

Allison, P. (2002). Missing data. Sage University papers series: Quantitative applications in the social sciences, no. 07-136. Sage.

Avolio, B. J., \& Bass, B. M. (2004). MLQ-Multifactor leadership questionnaire. Menlo Park: Mind Garden.

Bacharach, M., \& Gambetta, D. (2001). Trust in signs. In K. S. Cook (Ed.), Trust in society (pp. 148-184). Russell Sage Foundation.

Bass, B. M. (1999). Two decades of research and development in transformational leadership. European Journal of Work and Organizational Psychology, 8, 9-32.

Bass, B. M., Avolio, B. J., Jung, D. I., \& Berson, Y. (2003). Predicting unit performance by assessing transformational and transactional leadership. Journal of Applied Psychology, 88, 207-218.

Bedi, A., Alpaslan, C. M., \& Green, S. (2016). A meta-analytic review of ethical leadership outcomes and moderators. Journal of Business Ethics, 139, 517-536.

Blau, P. M. (1964). Exchange and power in social life. Wiley.

Boyle, R., \& Bonacich, P. (1970). The development of trust and mistrust in mixed mixed-motive games. Sociometry, 33(2), 123-139.

Burke, C. S., Sims, D. E., Lazzara, E. H., \& Salas, E. (2007). Trust in leadership: A multi-level review and integration. Leadership Quarterly, 18, 606-632.

Carlson, D. S., \& Perrewe, P. L. (1995). Institutionalization of organizational ethics through transformational leadership. Journal of Business Ethics, 14, 829-838.

Castaldo, S., Premazzi, K., \& Zerbini, F. (2010). The meaning(s) of trust: A content analysis on the diverse conceptualizations of trust in scholarly research on business relationship. Journal of Business Ethics, 96, 657-668.

Chen, G., Ployhart, R. E., Cooper-Thomas, H. D., Anderson, N., \& Bliese, P. D. (2011). The power of momentum: A new model of dynamic relationships between job satisfaction change and turnover decisions. Academy of Management Journal, 54, 159-181.

Cohen, J., \& Cohen, P. (1983). Applied multiple regression/correlation analysis for the behavioral sciences. Erlbaum.

Colquitt, J. A., Scott, B. A., \& LePine, J. A. (2007). Trust, trustworthiness, and trust propensity: A meta-analytic test of their unique relationships with risk taking and job performance. Journal of Applied Psychology, 92, 909-927.

Curran, P. J., \& Bauer, D. J. (2011). The disaggregation of within-person and between-person effects in longitudinal models of change. Annual Review of Psychology, 62, 583-619.

de Jong, B., \& Dirks, K. T. (2012). Beyond shared perceptions of trust and monitoring in teams: Implications of asymmetry and dissensus. Journal of Applied Psychology, 97, 391-406.

de Jong, B., Dirks, K. T., \& Gillespie, N. (2016). Trust and team performance: A meta-analysis of main effects, moderators, and covariates. Journal of Applied Psychology, 101, 1134-1150.

de Jong, B., Gillespie, N., Williamson, I., \& Gill, C. (2020). Trust consensus in within culturally diverse teams: A multi-study investigation. Journal of Management. https://doi.org/10.1177/01492 06320943658 
Dirks, K. T. (2000). Trust in leadership and team performance: Evidence from NCAA basketball. Journal of Applied Psychology, 85, 1004-1012.

Dirks, K., \& Ferrin, D. (2002). Trust in leadership: Meta-analytic findings and implications for research and practice. Journal of Applied Psychology, 87, 611-628.

Drescher, M. A., Korsgaard, M. A., Welpe, I. M., Picot, A., \& Wigand, R. T. (2014). The dynamics of shared leadership: Building trust and enhancing performance. Journal of Applied Psychology, 99(5), 771-783.

Edwards, J. R. (2001). Multidimensional constructs in organizational behavior research: An integrative analytical framework. Organizational Research Methods, 4(2), 144-192.

Edwards, J. R. (2002). Alternatives to difference scores: Polynomial regression analysis and response surface methodology. In F. Drasgow \& N. W. Schmitt (Eds.), Advances in measurement and data analysis (pp. 350-400). Jossey-Bass.

Edwards, J. R., \& Parry, M. E. (1993). On the use of polynomial regression equations as an alternative to difference scores in organizational research. Academy of Management Journal, 36(6), 1577-1613.

Enders, C. K., \& Bandalos, D. L. (2001). The relative performance of full information maximum likelihood estimation for missing data in structural equation models. Structural Equation Modeling: A Multidisciplinary Journal, 8(3), 430-457.

Ferrin, D. L., Bligh, M. C., \& Kohles, J. C. (2008). It takes two to tango: An interdependence analysis of the spiraling of perceived trustworthiness and cooperation in interpersonal and intergroup relationships. Organizational Behavior and Human Decision Processes, 107, 161-178.

Fulmer, C. A., \& Gelfand, M. J. (2013). How do I trust thee? Dynamic trust patterns and their individual and social contextual determinants. Models for intercultural collaboration and negotiation (pp. 97-131). Dordrecht: Springer.

Fulmer, C. A., \& Dirks, K. T. (2018). Mutlilevel trust: A theoretical and practical imperative. Journal of Trust Research, 8(2), 137-141.

Goldberg, L. R. (1992). The development of markers for the Big-Five factor structure. Psychological Assessments, 4(1), 26-42.

Grossman, R., \& Fetosa, J. (2018). Team trust over time: Modeling reciprocal and contextual influences in action teams. Human Resource Management Review, 28(4), 395-410.

Hall, R. J., \& Lord, R. G. (1995). Multi-level information processing explanations of followers' leadership perceptions. Leadership Quarterly, 6, 265-287.

Hoch, J. E., Bommer, W. H., Dulebohn, J. H., \& Wu, D. (2018). Do ethical, authentic, and Organizational Trust 57 servant leadership explain variance above and beyond transformational leadership? A meta-analysis. Journal of Management, 44, 501-529.

Jansen, K. J., Shipp, A. J., \& Michael, J. H. (2016). Champions, converts, doubters, and defectors: The impact of shifting perceptions on momentum for change. Personnel Psychology, 69, 673-707.

Kim, P. H., Ferrin, D. L., Cooper, C. D., \& Dirks, K. T. (2004). Removing the shadow of suspicion: The effects of apology vs. denial for repairing competence- vs. integrity-based trust violations. Journal of Applied Psychology, 89, 104-118.

Konovsky, M. A., \& Pugh, S. D. (1994). Citizenship behavior and social exchange. Academy of Management Journal, 37(3), 656-669.

Korsgaard, A. M., Kautz, J., Bliese, P., Samson, K., \& Kostyszyn, P. (2018). Conceptualising time as a level of analysis: New directions in the analysis of trust dynamics. Journal of Trust Research, $8(2), 142-165$.

Kramer, R. M., \& Lewicki, R. J. (2010). Repairing and enhancing trust: Approaches to reducing organizational trust deficits. The Academy of Management Annals, 4(1), 245-277.
Lewicki, R. J., Tomlinson, E. C., \& Gillespie, N. (2006). Models of interpersonal trust development: Theoretical approaches, empirical evidence, and future directions. Journal of Management, 32, 991-1022.

Lewicki, R. J., \& Bunker, B. B. (1996). Trust in relationships: A model of trust development and decline. In R. Kramer \& T. Tyler (Eds.), Trust in organizations (pp. 114-139). Sage Publications.

Lord, R. G., Foti, R., \& De Vader, C. (1984). A test of leadership categorization theory: Internal structure, information processing, and leadership perceptions. Organizational Behavior and Human Performance, 21, 343-378.

Macrae, C. N., \& Quadflieg, S. (2010). Perceiving people. In S. Fiske, D. Gilbert, \& G. Lindzey (Eds.), The handbook of social psychology (5th ed., pp. 428-463). Wiley \& Sons.

Mayer, R. C., Davis, J. H., \& Schoorman, F. D. (1995). An integrative model of organizational trust. Academy of Management Review, 20, 709-734.

McAllister, D. J. (1995). Affect- and cognition-based trust as foundations for interpersonal cooperation in organizations. Academy of Management Journal, 38, 24-59.

McKnight, D. H., Cummings, L. L., \& Chervany, N. L. (1998). Initial trust formation in new organizational relationships. Academy of Management Review, 23, 473-490.

Offermann, L. R., Kennedy, J. K., Jr., \& Wirtz, P. W. (1994). Implicit leadership theories: Content, structure, and generalizability. Leadership Quarterly, 5, 43-58.

Palanski, M. E., Kahai, S. S., \& Yammarino, F. J. (2011). Team virtues and performance: An examination of transparency, behavioral integrity, and trust. Journal of Business Ethics, 99(2), 201-216.

Palmatier, R., Houston, M., Dant, R. P., \& Grewal, D. (2013). Relationship velocity: Towards a theory of relationship dynamics. Journal of Marketing, 77, 13-20.

Parris, D. L., \& Peachey, J. W. (2013). A systematic literature review of servant leadership theory in organizational contexts. Journal of Business Ethics, 113, 377-393.

Parry, K. W., \& Proctor-Thomson, S. B. (2002). Perceived integrity of transformational leaders in organizational settings. Journal of Business Ethics, 35, 75-96.

Peus, C., Wesche, J. S., Streicher, B., Braun, S., \& Frey, D. (2012). Authentic leadership: An empirical test of its antecedents, consequences, and mediating mechanisms. Journal of Business Ethics, 107, 331-348.

Robinson, S. L. (1996). Trust and breach of the psychological contract. Administrative Science Quarterly, 41, 574-599.

Rosen, C. C., Dimotakis, N., Cole, M. S., Taylor, S. G., Simon, L. S., Smith, T. A., \& Reina, C. S. (2020). When challenges hinder: An investigation of when and how challenge stressors impact employee outcomes. Journal of Applied Psychology, 105, 1181-1206.

Rousseau, D. M., Sitkin, S. B., Burt, R. S., \& Camerer, C. (1998). Not so different after all: A cross-discipline view of trust. Academy of Management Review, 23, 393-404.

Serva, M. A., Fuller, M. A., \& Mayer, R. C. (2005). The reciprocal nature of trust: A longitudinal study of interacting teams. Journal of Organizational Behavior, 26, 625-648.

Siemsen, E., Roth, A., \& Oliveira, P. (2009). Common method bias in regression models with linear, quadratic, and interaction effects. Organizational Research Methods, 13, 456-476.

Spector, P. E. (2006). Method variance in organizational research: Truth or urban legend? Organizational Research Methods, 9, 221-232.

Su, H. Y. (2014). Business ethics and the development of intellectual capital. Journal of Business Ethics, 119, 87-98.

Tepper, B. J., Dimotakis, N., Lambert, L. S., Koopman, J., Matta, F. K., Man Park, H., \& Goo, W. (2018). Examining follower responses to transformational leadership from a dynamic, 
person-environment fit perspective. Academy of Management Journal, 61(4), 1343-1368.

Thibaut, J. W., \& Kelley, H. H. (1986). The social psychology of groups. Transaction Inc.

United States Military Academy. (2010). Building the capacity to lead: The west point system for leader development. West Point.

van der Werff, L., \& Buckley, F. (2017). Getting to know you: A longitudinal examination of trust cues and trust development during socialization. Journal of Management, 43, 742-770.

Vanneste, B. S., Puranam, P., \& Kretschmer, T. (2014). Trust over time in exchange relationships: Meta-analysis and theory. Strategic Management Journal, 35(12), 1891-1902.

Vogelgesang, G.R., Crossley, C., Simons, T. et al. (2021). Behavioral integrity: Examining the effects of trust velocity and psychological contract breach. Journal of Business Ethics, 172, 175-190.
Whitener, E. M., Brodt, S. E., Korsgaard, M. A., \& Werner, J. M. (1998). Managers as initiators of trust: An exchange relationship framework for understanding managerial trustworthy behavior. Academy of Management Review, 23(3), 513-530.

Xu, A. J., Loi, R., \& Ngo, H. (2016). Ethical leadership behavior and employee justice perceptions: The mediating role of trust in organization. Journal of Business Ethics, 143, 493-504.

Publisher's Note Springer Nature remains neutral with regard to jurisdictional claims in published maps and institutional affiliations. 